influenced the estimates of changes in incidence and mortality, although the systems used operated in the same way throughout the years studied.

The decline in incidence of myocardial infarction among men was seen over only two years, and it is too early to draw conclusions regarding the long term trend. If the decline continues, however, possible explanations should be investigated. Future data may indicate a turning point in the mortality from myocardial infarction in Stockholm and Sweden in general.

1 Piza Z, Uemura $\mathrm{K}$. Trends of mortality from ischaemic heart disease and other cardiovascular diseases in 27 countries 1968-77. World Health Stat $Q$ 1982;35:11-36.

2 Alfredsson L, Ahlbom A. Increasing incidence and mortality from myocardial infarction in Stockholm county. BrMed J 1983;286:1931-3.

3 Welin L, Larsson B, Svärdssud K, Wilhelmsen L, Tibblin G. Why is the incidence of ischaemic heart disease increasing? Study of men born 1913 and 1923. Lancet 1983;i:1087-8.

4 Ahlbom A. Acute myocardial infarction in Stockholm-a medical information system as an epidemiological tool. Int f Epidemiol 1978;7:271-6.

5 Breslow NW, Day NE. Indirect standardization and multiplicative models for rates, with reference to the age adjustment of cancer incidence and relative frequency data. $\mathcal{J}$ Chronic Dis 1975;28:289-303.

(Accepted 20 November 1986)

National Institute of Environmental Medicine, Box 60208, S-104 01

Stockholm, Sweden

NIKLAS HAMMAR, BA, research assistant

ANDERS AHLBOM, PHD, professor

Correspondence to: Mr Hammar.

\section{HIV infection and AIDS in newborn babies of mothers positive for HIV antibody}

Two thirds of the reported cases of the acquired immune deficiency syndrome (AIDS) in children have no risk factor except a mother belonging to a group with an increased prevalence of infection with human immunodeficiency virus (HIV). ${ }^{1}$ There is evidence of transplacental passage of the virus during early and late gestation, ${ }^{23}$ but the incidence of fetal and neonatal infection in newborn babies of seropositive mothers has not yet been determined. We present the clinical and serological outcome of 24 babies aged 6 months born to mothers who were drug addicts and positive for HIV antibodies.

\section{Patients, methods, and results}

In 1985, 31 pregnant intravenous drug abusers at the Center for Pregnant Drug Addicts of Milano, Italy, were identified as being positive for HIV antibodies by enzyme linked immunosorbent assay and Western blot analysis at the first obstetrical visit and confirmed again before delivery. All patients were followed up and delivered at this department.

All the women were clinically well except for one, who had generalised lymphadenopathy, fewer than $400 \mathrm{~T} 4$ lymphocytes $/ \mathrm{mm}^{3}$, and a low T4/T8 lymphocyte ratio. Nine women were primigravidas; 15 were secundigravidas, but only three were parous, reflecting a high incidence of elective abortions. All the pregnancies were singleton, 18 women being delivered vaginally and six by caesarean section (two babies in breech position, four suffering from intrapartum distress). All the babies were in good condition at birth with no malformations. The prevalence of premature delivery, fetal growth retardation, and early neonatal disease was comparable to that in the pregnant seronegative drug addicts. None of the babies was breast fed.

We obtained informed consent from the parents to follow up their babies. Clinical evaluations were performed at intervals of one month, and serological screening (enzyme linked immunosorbent assay and white blood cell count) and counts of T4 and T8 lymphocytes were performed on cord blood and at intervals of three months. At 6 months 12 babies were seropositive and 12 seronegative

Serological state of 24 babies at 6 months born to intravenous drug addicts positive for HIV antibody

\begin{tabular}{lccc}
\hline Delivery & No of babies & Seropositive & Seronegative \\
\hline Vaginal & 18 & $9^{\star}$ & 9 \\
Caesarean & 6 & 3 & 3 \\
\hline Total & 24 & 12 & 12 \\
\hline
\end{tabular}

$\star$ Died at 4 months from Pneumocystis carinii pneumonia. (table). One seropositive baby died of Pneumocystis carinii pneumonia at 4 months, and one seropositive baby was diagnosed as suffering from AIDS related complex at the age of 3 months. All the other babies thrived, the results of their follow up being entirely normal.

\section{Comment}

Our limited study shows that the prevalence of seropositivity in children aged 6 months, when all the maternal antibodies should have disappeared, is $50 \%$. Caesarean section does not seem to protect the fetus from infection, as has been suggested by one author and later refuted by the Center for Disease Control. ${ }^{4}$ This is consistent with the discovery of the virus in the fetal compartment in cases of elective caesarean section at 20 and 36 weeks. ${ }^{23}$

The two cases of immune deficiency acquired by maternal transmission of the virus indicate that early morbidity and mortality are a severe problem, but their incidence seems to be restricted to about $10 \%$ of the offspring. Unfortunately, nothing can yet be said about long term morbidity and mortality. These data may be helpful in counselling seropositive women before or in early gestation, as they suggest that the risk of fetal infection and severe postnatal morbidity is high. Unfavourable perinatal outcome, usually associated with drug addiction, was similar in seropositive and seronegative women: a detrimental effect of the virus in this regard was thus not evident.

Constant updating of available data will allow better counselling, more appropriate obstetrical care, prenatal diagnosis, and prompt treatment when effective treatment is available.

The Center for Pregnant Drug Addicts of Milano comprises Carmen Brescianini, Anna Bucceri, Anna Canestrari, Gabriele Ferraris, Isa Lodi, and Marina Ravizza.

1 Center for Disease Control. Recommendation for assisting in the prevention of perinatal transmission of human T-lymphotrophic virus type-III/ymphodanopathy associated virus and acquired immunodeficiency syndrome. MMWR 1985;34:48

2 Jovasias E, Koch MA, Schaefer A, Stauber M, Loewental D. LAV/HTLV-III in 20-week fetus. Lancet 1985 ;ii:1129.

3 Lapointe N, Michaud J, Pekovic D, Chausseau JP, Dupuy JM. Transplacental transmission of HTLV-III virus. $N$ Englf Med 1985;312:1325-6.

4 Lifson AR, Rogers MF. Vertical transmission of human immunodeficiency virus. Lancet 1986;ii:337

(Accepted 4 November 1986)

Department of Obstetrics and Gynecology, University of Milano

AUGUSTO E SEMPRINI, MD, senior research investigator of the National

Research Council

ALESSANDRA VUCETICH, $\mathrm{MD}$, resident

GIORGIO PARDI, MD, professor

Immunohematology Unit, Istituti Clinici di Perfezionamento, Milano MARIA MATILDE COSSU, MD, clinical assistan

Correspondence to: Dr A E Semprini, Clinica Mangiagalli, Via Commenda 12, 20122 Milano, Italy.

\section{Fall in intraocular pressure during acute hypoglycaemia in patients with insulin dependent diabetes}

In early studies of insulin induced hypoglycaemia in diabetic patients the development of "intraocular hypotonia" was noted"; the occurrence of a sudden decrease in intraocular pressure during severe, uncontrolled hypoglycaemia was later confirmed in five patients with insulin dependent diabetes of varying duration. ${ }^{2}$ To examine the magnitude of this decrease and its temporal relation to autonomic activation we measured intraocular pressure during controlled insulin induced hypoglycaemia in a group of insulin dependent diabetics.

\section{Patients, methods, and results}

As part of their diabetic education we exposed 12 insulin dependent diabetic patients aged 20-38 to a controlled episode of insulin induced hypoglycaemia with their informed consent. All patients were studied within one month after the diagnosis of diabetes; none had had metabolic decompensation at presentation. Satisfactory glycaemic control was established with a combination of short and intermediate acting human insulins given twice daily. None of the patients had diabetic retinopathy or had experienced blurring of vision after starting insulin treatment. Standard tests of cardiovascular reflexes gave normal results.

The patients were studied supine after an overnight fast, soluble human insulin 
BRITISH MEDICAL JOURNAL VOLUME $294 \quad 7$ MARCH 1987

$(0.2 \mathrm{U} / \mathrm{kg}$ ) (Humulin S, Lilly) being given intravenously. Blood glucose concentration fell to a nadir within 25-40 minutes (figure); this nadir coincided with the onset of the acute hypoglycaemic reaction, which was manifested by typical autonomic features, including sweating and tachycardia. Plasma adrenaline concentration, measured by a radioenzymatic assay, rose in all patients from a mean basal value of $0.34(\mathrm{SEM} 0 \cdot 08) \mathrm{nmol} / 1$ to a peak of $5 \cdot 2(1 \cdot 1) \mathrm{nmol} / 1$ 30 minutes after the nadir in plasma glucose concentration $(p<0.01)$. Plasma osmolality did not change in response to hypoglycaemia.
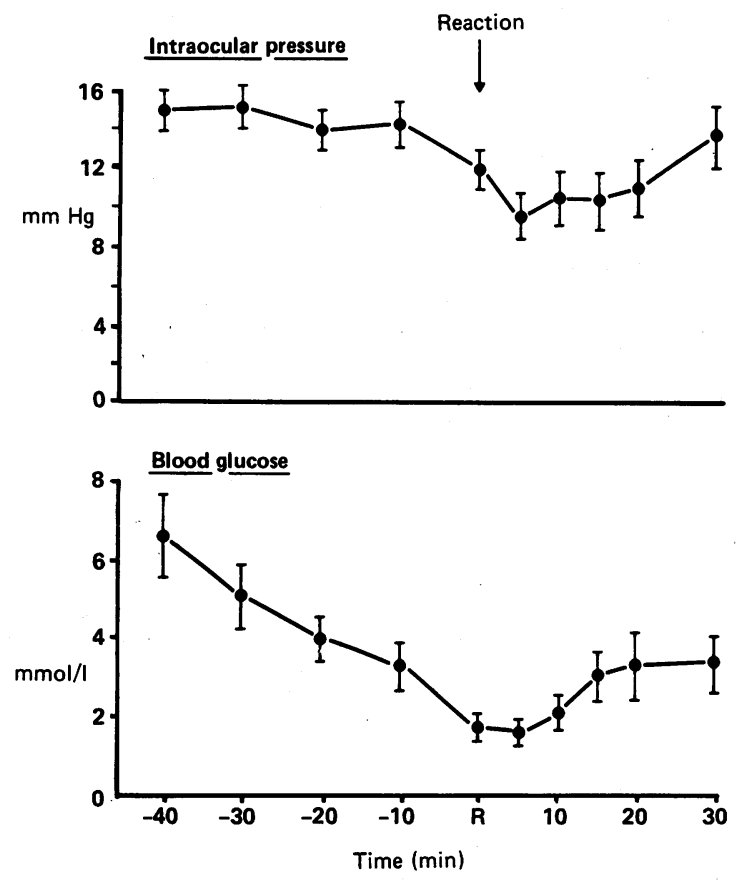

Mean (SEM) changes in intraocular pressure in right eye and blood glucose concentrations in response to insulin induced hypoglycaemia in 12 insulin dependent diabetics. All measurements were timed in relation to the acute hypoglycaemic reaction (R).

Intraocular pressures in both eyes were measured with a Perkins hand held aplanation tonometer; changes were similar in both eyes. In the left eye the mean basal pressure was $15 \cdot 2(1 \cdot 3) \mathrm{mm} \mathrm{Hg}$, which fell to $9 \cdot 8(0 \cdot 8) \mathrm{mm} \mathrm{Hg}$ five minutes after the nadir in plasma glucose concentration; and in the right eye the mean basal pressure was $15.2(1.5) \mathrm{mm} \mathrm{Hg}$, which fell to $9.7(1.3) \mathrm{mm} \mathrm{Hg}$ five minutes after the nadir in plasma glucose concentration (figure). The fall in intraocular pressures in both eyes was significant (basal $v$ nadir, $\mathrm{p}<0.005$; Student's $t$ test for paired data). In all patients intraocular pressures in both eyes returned to basal values within 30-40 minutes of the reaction.

\section{Comment}

In this group of patients with recently diagnosed diabetes the fall in intraocular pressure preceded the maximum rise in plasma adrenaline concentration; adrenaline is released in response to acute hypoglycaemia by activation of the sympathoadrenal system. Although adrenaline lowers intraocular pressure, the sudden fall coincided with the onset of the profound autonomic discharge provoked by acute hypoglycaemia. Both the sympathetic and parasympathetic components of the autonomic nervous system are activated, ${ }^{3}$ and the rapidity of the change in intraocular pressure suggests that it was mediated by the autonomic innervation to the eye and not primarily by circulating adrenaline. Autonomic innervation influences the rates of secretion and drainage of aqueous humour from the anterior chamber of the eye and so alters intraocular pressure. Conversely, raised intraocular pressure has been reported to be associated with autonomic dysfunction. ${ }^{4}$ Consistent changes in pupillary size in response to this degree of hypoglycaemia do not occur in normal subjects. ${ }^{3}$ Pupillary responses to light are often abnormal in patients with longstanding diabetes with autonomic neuropathy. ${ }^{5}$ Further evaluation of the effect of hypoglycaemia on intraocular pressure in diabetics with autonomic dysfunction may elucidate the neural mechanism underlying the changes in pressure.

Hypoglycaemia is a common side effect of insulin treatment in diabetic patients with good glycaemic control. Sudden changes in intraocular pressure may have potentially adverse effects on delicate and fragile capillaries produced during the neovascularisation of proliferative diabetic retinopathy. This represents a further hazard of hypoglycaemia for diabetic patients treated with insulin.

We thank the medical staff of the ophthalmology department and the laboratory staff of the biochemistry department, Gartnavel General Hospital, for valuable practical help with this study; $\mathrm{Mr}$ Gordon Inglis for assaying plasma adrenaline concentrations; and Miss Alison Wood for secretarial help.

1 Wiechmann E, Koch F. Untersuchungen über den hypoglykämischen Zustand nach Insulininjektion. Münchener Medizinische Wochenschrift 1927;74:1536-7.

2 Larsen H-W, Poulsen JE. Intraocular tension and blood-sugar fluctuations in diabetics. Acta Ophthalmol (Copenh) 1962;40:580-9.

3 Corrall RJM, Frier BM, Davidson NMcD, Hopkins WM, French EB. Cholinergic manifestations of the acute autonomic reaction to hypoglycaemia in man. Clin Sci 1983;64:49-53.

4 Clark CV, Mapstone R. Autonomic neuropathy in ocular hypertension. Lancet 1985;ii:185-7. 5 Smith SE, Smith SA. Reduced pupillary light reflexes in diabetic autonomic neuropathy. Diabetologia 1983;24:330-2.

(Accepted 12 November 1986)

Western Infirmary and Gartnavel General Hospital, Glasgow G12 0YN

B M FRIER, MD, FRCP, consultant physician, department of diabetes

D A HEPBURN, BMEDSCI, MB, senior house officer, department of diabetes B M FISHER, MB, MRCP, medical registrar, department of diabetes

T BARRIE, MB, FRCS, consultant ophthalmologist, department of ophthalmology

Correspondence to: Dr B M Frier, Level 7, Gartnavel General Hospital, Glasgow G12 OYN.

\section{Survival after burial in an avalanche}

A young woman buried for 20 minutes in snow, during which breathing must have been impossible, was resuscitated and survived without brain damage.

\section{Case report}

A 32 year old woman skier was carried $20 \mathrm{~m}$ by a wet snow avalanche before being buried for 20 minutes. She was located by an advancing line of searchers with probes. The snow over her was not stood on at any time. She was found in a prone position with her body angled up at $45^{\circ}$, her head being buried at a depth of about $0.75 \mathrm{~m}$ and her feet at $1.5 \mathrm{~m}$.

Her head was uncovered first; the mouth was not blocked with snow, but mouth to mouth resuscitation was not possible owing to the weight of snow surrounding her chest. When the chest was uncovered, ventilation was easy. On examination she was deeply unconscious and not breathing; she had a scarcely perceptible irregular carotid pulse of around 40 beats/minute. The mucous membranes were translucent grey white. She was wearing normal ski clothing but no hat; the clothing was dry. She was warmed with extra clothing and the sunshine. Mouth to mouth resuscitation was continued until spontaneous respiration returned after two minutes. Her pulse and colour gradually returned to normal. She regained consciousness slowly and was fully conscious after 20 minutes, shivering violently and complaining of extreme cold. She had no injuries and recovered fully, leaving hospital after two days.

\section{Comment}

Complete burial in a snow avalanche has only a $19 \%$ survival rate. ${ }^{1}$ Snow can weigh as much as $800 \mathrm{~kg} / \mathrm{m}^{3}$ (water weighs $1000 \mathrm{~kg} / \mathrm{m}^{3}$ ) and may freeze solid around a victim when the avalanche stops; as a result death is usually due to asphyxia. ${ }^{2}$ It is sometimes possible to breathe during burial, depending on factors such as air pockets between blocks of snow and lack of chest compression. This has been experienced by the few survivors who have remained conscious, enduring cold and extreme difficulty breathing. ${ }^{12}$

Anecdotal reports of survival after short periods of burial-for example five minutes-are numerous, but longer burial times-for example, 20 hours-are exceptional. ${ }^{12}$ The unique feature of this case is the demonstration that respiration could not have occurred, to any degree for the entire 20 minutes of burial, because of the weight of densely packed snow. I, being a registrar anaesthetist, was probably better able to judge this than other rescuers, who are usually laymen. As apnoea for 20 minutes normally results in death, important protective mechanisms must operate during burial in an avalanche.

Comparisons of surviving burial in an avalanche and immersion in cold water, when respiratory arrest and cooling also occur, can be made. Survival after as long as $\mathbf{4 0}$ minutes' immersion ${ }^{3}$ has been attributed to the protective effect of generalised hypothermia and the diving reflex, whereby facial 